(Journal of Civil Engineering, Building and Transportation)

\title{
Analisa Dampak Lalu Lintas Rumah Hunian Distric-9 Apartemen Terhadap Kemacetan Lalu Lintas di Kota Medan
}

\section{Analysis of Traffic Impact of Residential Houses District-9 Apartment Against Traffic Congestion in Medan City}

\author{
Rizqi* \& Edy Hermanto \\ Program Studi Teknik Sipil, Fakultas Teknik, Universitas Medan Area, Indonesia \\ *Coresponding Email: E-mail : rizqithaib@gmail.com
}

\section{Abstrak}

Rencana kegiatan pembangunan Rumah Hunian District-9 Apartment berada di Jalan Gedung Arca No. 5 Kelurahan Teladan Barat Kecamatan Medan Kota, Kota Medan-Sumatera Utara, diperkirakan dapat membangkitkan dan menambah beban lalu lintas. Hal ini tentunya berpengaruh pada kinerja jaringan jalan Gedung Arca yang merupakan jalan kota, sehingga bila bertambahnya volume pada ruas jalan tersebut secara signifikan tentu akan mengurangi tingkat pelayanan jalan. Untuk menghitung besaran dampak yang terjadi, maka dilakukan kajian dampak lalu lintas yang diharapkan dapat diminimalkan dengan memberikan solusi yang tepat. Berdasarkan hasil analisa yang telah dilakukan, diketahui od matriks asal tujuan perjalanan sebelum pembangunan Districk-9 Apartement yaitu dilakukan perjalanan sebesar $7470 \mathrm{Smp} / \mathrm{Jam}$. Kinerja ruas jalan tertinggi sebelum pembangunan yaitu ruas jalan Sisimangaraja V/C rasionya 0.78 dengan level of service $\mathrm{D}$ dan ruas jalan M. Joni Segmen $1 \mathrm{~V} / \mathrm{C}$ rasionya 0.76 dengan level of service D, sedangkan ruas jalan Gedung Arca segmen 3 yang merupakan jalan di depan lokasi pembangunan pada saat kondisi eksisting atau sebelum pembangunan $\mathrm{V} / \mathrm{C}$ rasionya 0.54 dengan level of service C. Berdasarkan hasil analisa yang telah dilakukan, kinerja jaringan jalan sebelum pembangunan yaitu journey time 233,4 kend/jam, distance traveled 6996,5 kend/jam, konsumsi bahan bakar 631.6 liter, network speed $30 \mathrm{Km} / \mathrm{Jam}$.

Kata Kunci : Analisa Dampak Lalu Lintas, Rumah Hunian, Kinerja Ruas Jalan, Kemacetan.

\begin{abstract}
Plans for the construction of Residential Houses District-9 Apartment is located at Jalan Arca Building No. 1. 5 Kelurahan Teladan Barat Medan City District, Medan-North Sumatera City, is expected to generate and increase the traffic load. This of course affects the performance of the Arca Street building network which is the city road, so if the increase in volume on the road segment will significantly reduce the level of road service. To calculate the magnitude of the impacts, then a traffic impact assessment is expected to be minimized by providing the right solution. Based on the results of the analysis that has been done, it is known od matrix of the origin of the trip prior to the construction of Districk-9 Apartement is a trip of $7470 \mathrm{Smp} / \mathrm{Jam}$. The highest road performance before the construction of the Sisimangaraja $\mathrm{V} / \mathrm{C}$ road is 0.78 with the level of service $D$ and the $M$. Joni Segment $1 \mathrm{~V} / \mathrm{C}$ segment ratio is 0.76 with the level of service D, whereas the segment 3 streets of Jalan Gedung Arca in front of the construction site at the time of the existing condition or before the construction of the $V / C$ ratio is 0.54 with the level of service $C$. Based on the results of the analysis that has been done, the road network performance before the journey time is 233.4 kend / jam, distance traveled 6996,5 kend / hour, 631.6 liter fuel consumption, network speed $30 \mathrm{Km} / \mathrm{Jam}$.
\end{abstract}

Keywords: Traffic Impact Analysis, Shelter, Road Performance, Congestion.

How to Cite: Rizqi, \& Hermanto, E. (2017). Analisa Dampak Lalu Lintas Rumah Hunian Distric-9 Apartemen Terhadap Kemacetan Lalu Lintas di Kota Medan, JCEBT (Journal of Civil Engineering, Building and Transportation). 1 (2): 70-79. 


\section{PENDAHULUAN}

Rencana kegiatan pembangunan Rumah Hunian District-9 Apartment berada di Jalan Gedung Arca No. 5 Kelurahan Teladan Barat Kecamatan Medan Kota, Kota Medan-Sumatera Utara, diperkirakan dapat menarik dan membangkitkan lalu lintas yang akan menambah beban lalu lintas. Tentunya hal ini berpengaruh pada kinerja jaringan jalan Gedung Arca yang merupakan jalan Kota, sehingga apabila bertambahnya volume pada ruas jalan tersebut secara signifikan tentu akan mengurangi tingkat pelayanan jalan tersebut.

Menghitung besaran dampak yang diperkirakan oleh Pembangunan Rumah Hunian District-9 Apartment di Kota Medan dengan menganalisis besaran dampak lalu lintas yang timbul dari pembangunan baik pada tahap konstruksi dan tahap operasi. Analisis ini dapat mengantisipasi dampak yang ditimbulkan terhadap jaringan jalan yang ada di sekitarnya.

Prediksi dampak yang ditimbulkan dari Pembangunan Rumah Hunian District9 Apartment di kota Medan, tentunya menentukan bentuk peningkatan/perbaikan yang diperlukan. Tentunya untuk mengakomodasikan perubahan yang terjadi akibat pengembangan aktivitas tata guna yang berubah, menyelaraskan keputusankeputusan mengenai tata guna lahan dengan kondisi lalu lintas dan jaringan jalan serta sebagai alat pengawasan dan evaluasi terhadap pelaksanaan manajemen dan rekayasa lalu lintas dari solusi penanganan dampak lalu lintas.

Dari adanya analisis tersebut, maka akan didapatkan inventarisasi data dukung (data sekunder) Pembangunan Rumah Hunian District-9 Apartment di kota Medan yang meliputi luas lahan, luas bangunan, lebar jalan keluar - masuk dan rencana gambar tapak (site plan). Inventarisasi kondisi prasarana jalan (inventarisasi geometrik ruas jalan) meliputi, jarak lokasi terhadap jalan utama, lebar jalan, arah lalu lintas, desain jalan, inventarisasi fasilitas perlengkapan jalan (rambu, marka jalan dsb) dan kondisi lingkungan jalan. Inventarisasi data lalu lintas dengan melakukan perhitungan volume lalu lintas terklasifikasi dari berbagai jenis kendaraan yang melintas di jalan utama (jalan depan lokasi). Melakukan analisis kinerja dan tingkat pelayanan jalan atau kondisi rona Rumah Hunian District-9 Apartment di kota Medan sebelum dibangun. Melakukan analisis kinerja dan tingkat pelayanan jalan pada tahap konstruksi (pengembangan) dan tahap operasi 
(Rumah Hunian District-9 Apartment di kota Medan sudah terbangun). Melakukan solusi penanganan dampak lalu lintas yang terjadi, dengan meminimalkan konflik kendaraan yang keluar-masuk Rumah Hunian District-9 Apartment di kota Medan terhadap lalu lintas menerus, menata sirkulasi pergerakan kendaraan di dalam lokasi, menata dan menghitung kebutuhan tempat parkir.

\section{METODE PENELITIAN}

Pengumpulan data primer, diperoleh dengan cara pengamatan langsung di lapangan yang berkaitan dengan tujuan penelitian. Data primer ini dibutuhkan untuk menganalisis kinerja jaringan jalan yang terkena dampak terhadap kegiatan

Kegiatan Pembangunan Districk 9 Apartment. Pengumpulan data sekunder didapatkan dari berbagai instansi terkait, seperti Bappeda Kota Medan, Dishub Kota Medan, Kantor Statistik Kota Medan, dan Districk 9 Apartment dan lain - lain.

\section{HASIL DAN PEMBAHASAN}

\section{Distribusi Perjalanan Sebelum}

\section{Pembangunan Districk 9 Apartement}

Pada tahap ini dibahas mengenai Distribusi Perjalanan eksisting pada tahun 2015 dimana diasumsikan belum adanya pembangunan Districk 9 Apartemen dimana distribusi yang dimaksud menghasilkan O/D matriks asal tujuan perjalanan.

Untuk mengetahui O/D matriks asal tujuan perjalanan pada pembangunan Distrik 9 Apartemen tersebut maka O/D Matriks tersebut dibantu dengan program computer COMEST8 (Constrained O-D Matrik Estimation), adapun OD matriks asal tujuan perjalanan Sebelum pembangunan tahun 2015 adalah sebagai berikut.

Tabel 1. OD Matriks Asal Tujuan Perjalanan Districk 9 Apartemen Sebelum Pembangunan

\begin{tabular}{llllllll}
\hline OD & 1 & 2 & 3 & 4 & 5 & 6 & PJ \\
1 & 0 & 545 & 381 & 122 & 45 & 56 & 1149 \\
2 & 680 & 0 & 1156 & 161 & 131 & 345 & 2473 \\
3 & 134 & 1455 & 0 & 145 & 127 & 145 & 2006 \\
4 & 67 & 117 & 127 & 0 & 138 & 123 & 572 \\
5 & 43 & 112 & 166 & 83 & 0 & 201 & 605 \\
6 & 276 & 56 & 43 & 167 & 123 & 0 & 665 \\
AJ & 1200 & 2285 & 1873 & 678 & 564 & 870 & 7470 \\
\hline
\end{tabular}

Sumber: Hasil Analisis Konsultan

Dari hasil program computer COMEST8 (Constrained O-D Matrik Estimation) maka didapat OD matriks asal tujuan perjalanan pembangunan Districk 9 Apartemen, dapat diketahui dari matriks OD tersebut bahwa perjalanan pada tahun 2015 sebelum Pembangunan Districk 9 Apartemen sebesar 7470 Smp/Jam dan perjalanan terbesar adalah dari zona $3 \mathrm{ke}$ 2 dengan perjalanan 1455 Smp/jam. Hasil Program computer comest8 terlampir. 
Tabel 2. Kinerja jaringan jalan kawasan

Districk-9 Apartemen sebelum pembangunan

\begin{tabular}{ll}
\hline $\begin{array}{l}\text { Perameter kinerja } \\
\text { jaringan }\end{array}$ & Jumlah \\
\hline Journey time & 233.4 Kend/Jam \\
Distence traveled & $6996.5 \mathrm{Kend} / \mathrm{Km}$ \\
Feul consumption & 631.6 Liter \\
Network speed & 30 km/jam \\
\hline
\end{tabular}

Sumber: Hasil Analisis

Dari hasil analisis menggunakan program komputer Contram versi 5.09 diketahui bahwa kinerja jaringan jalan pada kawasan Districk 9 Apartemen diketahui journey time 233,4 kend/jam, Distence Traveled 6996,5 kend/jam, Fuel consumption 631.6 Liter, Network Speed 30 $\mathrm{Km} / \mathrm{Jam}$.

Dengan taraf signifikansi $5 \%$ atau tingkat kepercayaan 95\% dan jumlah data 36 maka didapat tabel $\mathrm{x}^{2}$ sebesar 43.77. Hasil perhitungan chi square antara volume observasi dengan volume model diperoleh total nilai 39.5. Hal ini menunjukan bahwa hasil perhitungan dibawah nilai tabel $\mathrm{x}^{2}$ tidak jauh berbeda. Hal ini menunjukan bahwa model valid dan dapat digunakan. Berikut adalah contoh perhitungan uji square.

Rumus :

$\mathrm{RUX}^{2}=\mathrm{X}^{2}=\sum[((\mathrm{O}-\mathrm{E}) 2) / \mathrm{E}]$

(volume survai - volume model) ${ }^{2}$

$$
\begin{aligned}
& =(1133-1149) \\
& =(-16)^{2} \\
& =374.4 / 1366 \\
& =0.2
\end{aligned}
$$

Uji Chi Kuadrat dilakukan dengan kriteria sebagai berikut:

a) Hipotesis:

$\mathrm{H}_{0}$ : hasil survai $=$ hasil model
$\mathrm{H}_{1}$ : hasil survai $\neq$ hasil model

b) Batas-batas daerah penolakan/batas kritis uji:

Dari tabel $\mathrm{X}^{2}$ untuk $\alpha=0,05 ; \mathrm{df}=6$ diperoleh X2=43,77 dan Hasil selisish angka dari Volume Survei dan volume model Contram 39.5 maka model dapat diterima.

Berdasarkan Hasil Analisa yang telah dilakukan oleh consultan diketahui Od Matriks Asal Tujuan Perjalanan Sebelum Pembangunan Districk 9 Apartemen yaitu melakukan perjalanan sebesar 7470 Smp/Jam. Dapat diketahui Kinerja Ruas Jalan tertinggi sebelum pembangunan Districk 9 Apartemen yaitu ruas jalan Sisimangaraja V/C rasionya 0.78 dengan level of service D dan ruas jalan M.Joni Segmen $1 \mathrm{~V} / \mathrm{C}$ rasionya 0.76 dengan level of service D, Sedangkan Ruas Jalan Gedung arca Segmen 3 yang merupakan jalan didepan lokasi pembangunan pada saat kondisi eksisting atau sebelum pembangunan $\mathrm{V} / \mathrm{C}$ rasionya 0.54 dengan level of service $\mathrm{C}$.

Berdasarkan hasil analisa yang telah dilakukan oleh konsultan Kinerja Jaringan Jalan sebelum pembangunan diketahui journey time 233,4 kend/jam, distence 
traveled 6996,5 kend/jam, feul consumtion 631.6 liter, Network Speed 30 Km/Jam.

Kinerja Jaringan Jalan Sebelum Pembangunan Districk 9 Apartemen Pada Tahun 2020 Atau 5 Tahun Kedepan (Peramalan Asal Tujuan Perjalanan Tahun 2020 Sebelum Pembangunan)

Pada tahap ini, dilakukan peramalan terhadap kondisi lalu lintas yang ada, dengan menggunakan asumsi bahwa pertumbuhan kepemilikan kendaraan bermotor di Kota Medan sebesar 6,8\% pertahun. Adapun tahun rencana adalah tahun 2020. Pada kondisi ini prasarana dan lainnya dianggap tetap, hanya volume lalu lintasnya yang meningkat Dalam Peramalan Distribusi Perjalanan pada tahun 2020 maka menggunakan rumus:

$$
\mathrm{PT}=\mathrm{PO} \times(1+\mathrm{i})^{\wedge} \mathrm{n}
$$

\section{Keterangan:}

$\mathrm{Pt}=$ Pertumbuhan lalu lintas tahun ke-n

Po = Lalu lintas tahun eksisting

$\mathrm{i}=$ Faktor pertumbuhan

$\mathrm{n}$ = Jumlah tahun

Setelah Diramalkan Perjalanan pada tahun 2020 sebelum pembangunan Districk 9 Apartemen Berikut adalah OD matriks asal tujuan perjalanan pada tahun 2020 sebelum pembangunan.
Tabel 3. OD Matriks Asal Tujuan

Perjalanan Tahun 2020 Sebelum

Pembangunan Districk 9 Apartemen

\begin{tabular}{llllllll}
\hline OD & 1 & 2 & 3 & 4 & 5 & 6 & PJ \\
1 & 0 & 757 & 529 & 170 & 63 & 78 & 1597 \\
2 & 945 & 0 & 1606 & 224 & 182 & 479 & 3436 \\
3 & 186 & 2022 & 0 & 201 & 176 & 201 & 2787 \\
4 & 93 & 163 & 176 & 0 & 192 & 171 & 795 \\
5 & 60 & 156 & 231 & 115 & 0 & 279 & 841 \\
6 & 383 & 78 & 60 & 232 & 171 & 0 & 924 \\
AJ & 1667 & 3175 & 2603 & 942 & 784 & 1209 & 10380 \\
\hline
\end{tabular}

Sumber: Hasil Analisis

Dari hasil peramalan asal tujuan perjalanan tahun 2020 sebelum pembangunan Districk 9 Apartemen diketahui Total perjalanan pada tahun 2020 pada kawasan Districk 9 Apartemen sebelum pembangunan menjadi 10380 Smp/Jam. Hal ini tentu akan berpengaruh terhadap kinerja jaringan jalan di sekitar pembangunan Districk 9 Apartemen.

Setelah dilakukan peramalan Jumlah Perjalanan asal tujuan kendaraan pada tahun 2020 menjadi 10380 Smp/Jam. Dapat diketahui Kinerja Ruas Jalan tahun 2020 sebelum pembangunan Kinerja Ruas jalan di jalan Gedung Arca Segmen $4 \mathrm{~V} / \mathrm{C}$ Rasionya 0,79 dengan level of service D dan Ruas disekitarnya yang kinerja ruas nya tertinggi terletak dijalan Jl. Sisimangaraja V/C Rasionya 1 dengan level of service F, Jl. M Joni segmen 1 V/C Rasio 1 dengan level of service F, Jl. Stadion Segmen $7 \mathrm{~V} / \mathrm{C}$ rasionya 1 dengan level of service $\mathrm{F}$.

Diketahui Kinerja Jaringan Jalan Tahun 2020 sebelum pembangunan yaitu journey time 324.3 kend/jam, distrence traveled 9722 Kend/Jam, feul consumtion 
899,9 liter dan network speed 18,6 Pembangunan. Adapun metode yang $\mathrm{Km} / \mathrm{Jam}$. digunakan adalah dengan melakukan perbandingan terhadap bangkitan dan

Kinerja Jaringan Jalan Sesudah tarikan dari studi yang pernah dilakukan Beroperasinya Districk 9 Apartemen sebelumnya (comparison method). Untuk Peramalan Bangkitan Dan Tarikan menganalisis bangkitan dan tarikan maka Perjalanan Pembangunan Districk 9 dilakukan dengan study comparison Apartemen.

Pada tahap ini, akan diramalkan ditunjukkan pada tabel berikut. besaran bangkitan dan tarikan dari

Tabel 4. Study Comparison Method

\begin{tabular}{|c|c|c|c|c|}
\hline \multirow{2}{*}{ Jenis Peruntukan Lahan } & \multicolumn{2}{|c|}{ Peak Pagi } & \multicolumn{2}{|c|}{ Peak Sore } \\
\hline & Masuk & Keluar & Masuk & Keluar \\
\hline Perkantoran (smp/1oom² luas kotor) & 1.17 & 0.46 & 0.8 & 0.98 \\
\hline Pusat Pembelanjaan (smp/10om² luas kotor) & $\begin{array}{l}0.17 \\
(0.25)^{*}\end{array}$ & $\begin{array}{l}0.08 \\
(0.25)^{*}\end{array}$ & $\begin{array}{l}0.68 \\
(1.45)^{*}\end{array}$ & $\begin{array}{l}0.81 \\
(1.68)^{*}\end{array}$ \\
\hline Hotel (smp/jumlah kamar) & 0.82 & 0.21 & 0.27 & 0.27 \\
\hline Residential (smp/unit) & 0.06 & 0.25 & 0.25 & 0.12 \\
\hline Apartemen (smp/Kamar) & 0.2 & 0.88 & 0.29 & 0.2 \\
\hline Gedung Pertemuan (smp/10om² luas kotor) & - & - & - & - \\
\hline Sekolah (smp/10om² luas kotor) & - & - & - & - \\
\hline Pergudangan & 0.32 & 0.38 & 0.36 & 0.39 \\
\hline
\end{tabular}

Sumber: Study Comparison Method

Dari tabel di atas maka jenis Districk 9 Apartemen yaitu tipe A peruntukan yang diambil adalah sebanyak 24 Kamar, Tipe B sebanyak 48 apartemen berdasarkan study comparison Kamar dan tipe C sebanyak 8 kamar dan method. Untuk Apartemen diambil untuk pusat perdagangan berupa kios koefisien 0.2 untuk masuk dan 0.88 untuk disediakan 28 Unit. Dari hal tersebut maka keluar pada peak pagi dan untuk peak sore diambil 0.29 masuk dan 0.2 keluar. Berikut adalah bangkitan dan tarikan perjalanan yang disebabkan pembangunan Districk 9 Apartemen.

Kegiatan yang direncanakan oleh pengembang pada saat operasional Districk 9 Apartement yaitu penyewaan kamar dan kios. Jumlah kamar yang direncanakan dalam pembangunan dapat diramalkan bangkitan dan tarikan perjalanan yang disebabkan oleh Pembangunan Districk 9 Apartemen pada Tabel 5 dan Tabel 6.

Dari hasil analisa yang telah dilakukan diprediksi bangkitan perjalanan yang disebabkan oleh Districk 9 Apartemen terjadi pada pagi hari dengan perjalanan 77 Smp/Jam dan tarikan perjalanan terjadi pada sore hari dengan 
perjalanan $64 \mathrm{Smp} / J a m$. Berikut adalah kodefikasi jaringan jalan setelah pembangunan Districk 9 Apartemen.

Tabel 5. Bangkitan dan Tarikan Districk 9 Apartemen (Peak Pagi)

\begin{tabular}{|c|c|c|c|}
\hline $\begin{array}{l}\text { Jenis } \\
\text { kegiatan }\end{array}$ & $\begin{array}{l}\text { Jumlah } \\
\text { (Unit) }\end{array}$ & $\begin{array}{l}\text { Peak pagi } \\
\text { Tarikan }\end{array}$ & Bangkitan \\
\hline Apartemen & 80 & 16 & 70 \\
\hline Kios & 28 & 7 & 7 \\
\hline Total & & 23 & 77 \\
\hline
\end{tabular}

Sumber: Hasil Analisis Konsultan

Tabel 6. Bangkitan dan Tarikan Districk 9 Apartemen (Peak Sore)

\begin{tabular}{llll}
\hline $\begin{array}{l}\text { Jenis } \\
\text { kegiatan }\end{array}$ & $\begin{array}{l}\text { Jumlah } \\
\text { (Unit) }\end{array}$ & $\begin{array}{l}\text { Peak sore } \\
\text { Tarikan }\end{array}$ & Bangkitan \\
\hline Apartemen & 80 & 23 & 16 \\
Kios & 28 & 41 & 47 \\
Total & & 64 & 63 \\
\hline
\end{tabular}

Sumber: Hasil Analisis Konsultan

Setelah dilakukan analisa bangkitan dan tarikan perjalanan Districk 9 Apartemen diprediksi bangkitan perjalanan yang disebabkan oleh Districk 9 Apartemen terjadi pada pagi hari dengan perjalanan 77 Smp/Jam dan tarikan perjalanan terjadi pada sore hari dengan perjalanan $64 \mathrm{Smp} / \mathrm{Jam}$.

Diketahui Setelah Pembangunan Districk 9 Apartement diketahui OD Matriks Asal tujuan Perjalanan disekitar Districk 9 Apartemen menjadi 7547 Smp/Jam. Diketahui Setelah pembangunan Distrik 9 Apartement Kinerja Ruas Jalan Gedung Arca yaitu V/C rasionya menjadi 0.57 dengan level of service $\mathrm{C}$.
Setelah dilakukan analisa oleh konsultan kinerja jaringan jalan setelah pembangunan Districk 9 Apartement diketahui journey time 238,8 kend/jam, distrence traveled 7171,8 Kend/Jam, feul consumtion 644,9 liter dan network speed $18,6 \mathrm{Km} / \mathrm{Jam}$.

\section{Distribusi Perjalanan Setelah Districk 9}

\section{Apartemen Terbangun.}

Setelah diramalkan jumlah bangkitan dan tarikan Districk 9 Apartemen, tahap selanjutnya yaitu pendistribusian perjalanan yang ditunjukan dalam OD matriks Asal tujuan perjalanan setelah pembangunan Districk 9 Apartemen. Berikut adalah OD matriks Asal Tujuan Perjalanan Districk 9 Apartemen Setelah Pembangunan.

Dari OD Matriks Asal Tujuan Perjalanan dibawah (Tabel 7) setelah terbangunnya Disrick 9 Apartemen maka Perjalanan Pada kawasan tersebut menjadi 7547 Smp/Jam. 

Rizqi \& Edy Hermanto. Analisa Dampak Lalu Lintas Rumah Hunian Distric-9 Apartemen terhadap

Tabel 7. OD Matriks Asal Tujuan Perjalanan Setelah Districk 9 Apartemen Terbangun

\begin{tabular}{lllllllll}
\hline OD & 1 & 2 & 3 & 4 & 5 & 6 & 7 & PJ \\
1 & 0 & 545 & 381 & 122 & 45 & 56 & 15 & 1149 \\
2 & 680 & 0 & 1156 & 161 & 131 & 345 & 10 & 2473 \\
3 & 134 & 1455 & 0 & 145 & 127 & 145 & 9 & 2006 \\
4 & 67 & 117 & 127 & 0 & 138 & 123 & 10 & 572 \\
5 & 43 & 112 & 166 & 83 & 0 & 201 & 11 & 605 \\
6 & 276 & 56 & 43 & 167 & 123 & 0 & 9 & 665 \\
7 & 19 & 11 & 12 & 10 & 13 & 12 & 0 & 77 \\
AJ & 1219 & 2296 & 1885 & 688 & 577 & 882 & 64 & 7547 \\
\hline \multicolumn{7}{c}{ Sumber: Hasil Analisis }
\end{tabular}

Kinerja Jaringan Jalan Sekitar Districk 9 Apartemen Setelah Pembangunan.

Pada tahap ini dibahas mengenai perjalanan 238,8 kend/jam, jarak tempuh 7171,8 Kend/Jam, konsumsi bahan bakar Kinerja Jaringan Jalan Setelah pembangunan Disrick 9 Apartemen. Hal ini dilakukan untuk melihat besaran dampak yang disebabkan oleh Districk 9 Apartemen setelah terbangun terhadap kinerja jaringan jalan sekitar.

Analisis Kinerja Jaringan Jalan akan dilakukan menggunakan Program komputer yaitu Contram versi 5.09. Dari hasil analisa yang dilakukan menggunakan program computer Contram versi 5.09 diketahui bahwa kinerja jaringan jalan terburuk adalah Jl. Sisimangaraja segmen 1 dengan $\mathrm{V} / \mathrm{C}$ ratio 0.79 dengan level of service D. Berikut adalah kinerja jaringan jalan setelah pembangunan Districk 9 Apartemen.

Dari hasil analisis yang telah dilakukan menggunakan program computer Contram versi 5.09, diketahui kinerja jaringan jalan Districk 9 Apartemen terbangun yaitu waktu 644,9 Liter dan kecepatan jaringan 18,6 $\mathrm{Km} / \mathrm{Jam}$.

Tabel 8. Kinerja Jaringan Jalan Setelah Districk 9 Apartemen Terbangun

\begin{tabular}{ll}
\hline Perameter kinerja jaringan & Jumlah \\
\hline Waktu perjalanan & 238.8 kend/jam \\
Jarak tempuh & $7171.8 \mathrm{kend} / \mathrm{km}$ \\
Konsumsi bahan bakar & $644.9 \mathrm{liter}$ \\
Kecapatan jaringan & $29 \mathrm{~km} / \mathrm{jam}$ \\
\hline
\end{tabular}
Sumber: Hasil Analisis Konsultan Setelah dilakukan analisa bangkitan dan tarikan perjalanan Districk 9 Apartemen diprediksi bangkitan perjalanan yang disebabkan oleh Districk 9 Apartemen terjadi pada pagi hari dengan perjalanan 77 Smp/Jam dan tarikan perjalanan terjadi pada sore hari dengan perjalanan $64 \mathrm{Smp} / \mathrm{Jam}$.

Diketahui Setelah Pembangunan Districk 9 Apartement diketahui OD Matriks Asal tujuan Perjalanan disekitar Districk 9 Apartemen menjadi 7547 Smp/Jam. Diketahui Setelah pembangunan Distrik 9 Apartement Kinerja Ruas Jalan 
Gedung Arca yaitu V/C rasionya menjadi 0.57 dengan level of service $\mathrm{C}$.

Setelah dilakukan analisa oleh konsultan kinerja jaringan jalan setelah pembangunan Districk 9 Apartement diketahui journey time 238,8 kend/jam, distrence traveled 7171,8 Kend/Jam, feul consumtion 644,9 liter dan network speed $18,6 \mathrm{Km} / \mathrm{Jam}$.

Upaya Penanganan Dampak Lalu Lintas Pada Saat Kontruksi Districk 9 Apartement.

1. Pada pintu keluar-masuk kendaraan proyek Distrik 9 Apartemen perlu menempatkan petugas untuk mengatur lalu lintas kendaraan proyek yang dilengkapi dengan peralatan yang lengkap.

2. Melarang kendaraan proyek parkir dibadan jalan agar tidak mengurangi kapasitas jalan yang ada.

3. Menempatkan dan menyimpan peralatan berat didalam lokasi proyek.

4. Pengangkutan material bangunan menghindari jam-jam sibuk, agar tidak mengganggu arus lalu lintas secara signifikan.

5. Menyediakan tempat parkir kendaraan untuk pekerja proyek Distrik 9 Apartemen.

6. Melengkapi kendaraan proyek yang mengangkut material yang mudah tercecer dengan penutup yang memadai, agar tidak menimbulkan ceceran tanah dan material dijalan sekitar lokasi proyek, serta dijalan yang dijadikan rute pengangkut material bangunan yang dilalui oleh kendaraan proyek pada saat pembangunan untuk menghindari tergelincirnya kendaraan lain, khususnya pengendara sepeda motor.

7. Membersihkan jalan di sekitar lokasi proyek Districk 9 Apartemen jika terdapat ceceran material dengan menyiramnya.

8. Roda kendaraan pengangkut material pada saat akan keluar dari lokasi proyek dengan menyediakan/membuat water trap di akses pintu keluar-masuk lokasi proyek, untuk membersihkan tanah/kotoran yang masih melekat pada permukaan ban kendaraan proyek/truk pengangkut material sehingga dapat meminimalisasi ceceran debu di jalan-jalan yang dilalui.

9. Memasang lampu penerangan jalan pada saat melakukan aktivitas proyek pada malam hari.

10. Memasang papan informasi tentang kegiatan pembangunan/proyek seperti "hati-hati, kurangi kecepatan, 100 m lagi sering keluar-masuk kendaraan proyek“, dan diulang pada jarak 50 m sebelum proyek dari arah utara dan 
selatan serta rambu petunjuk di depan pintu keluar-masuk.

11. Meningkatkan struktur jalan masuk untuk mendukung mobilisasi kendaraan material keluar-masuk lokasi.

12. Menggunakan kendaraan truk yang tidak melebihi dari daya dukung jalan yang ada pada saat mengangkut material untuk pembangunan Districk 9 Apartemen.

\section{SIMPULAN}

Penanganan Dampak Lalu Lintas Operasional Districk 9 Apartement: melakukan Manajemen lalu Lintas Dengan Sistem 1 Arah diKawasan Districk 9 Apartemet. Manajemen Rekayasa Lalu Lintas pada Kawasan Districk 9 Apartement dengan memasang perlengkapan jalan yang diusulkan berupa rambu dan marka yaitu 4 rambu 1 arah yang dipasang dijalan Stadion dan Jl. Gedung Arca, 8 Buah rambu larangan parkir yang dipasang di jalan Stadion sebanyak 5 buah dan 3 buah di jalan Gedung Arca, 2 buah rambu petunjuk pejalan kaki yang dipasang di jalan Stadion dan Jalan Gedung Arca, 1 buah rambu pembatas kecepatan $40 \mathrm{Km} / \mathrm{Jam}$ yang dipasang dijalan gedung arca, 1 Buah rambu wajib belok kiri yang dipasang jalan pelajar, rambu larangan belok kanan dan belok kiri dan kanan yang dipasang dijalan stadion dan jalan pelajar, 1 buah Rambu petunjuk halte yang dipasang dijalan gedung arca, pemasang rubble strip yang dipasang dijalan gedung arca, pemasangan cermin jalan yang dipasang dipintu masuk dan keluar Districk 9 Apartement. Untuk menghindari gangguan kelancaran lalu lintas akibat naik turun penumpang angkutan umum di depan lokasi Distric 9 Apartemen, maka pihak pengembang harus menyediakan halte sebagai sarana untuk penumpang angkutan umum dan agar tidak terjadi gangguan kelancaran lalu lintas yang disebabkan oleh angkutan umum yang menurunkan dan menaikan penumpang dihalte maka harus membuat celukan didepan lokasi sebagai tempat pemberhentian angkutan umum agar dalam menaikan atau menurunkan penumpang tidak mengganggu kelancaran lalu lintas menerus di jalan depan lokasi Districk 9 Apartemen. Berdasarkan hasil perhitungan tersebut di mana $\mathrm{PV}^{2}$ adalah 1 x $10^{8}$ yang didasari oleh volume kendaraan dan jumlah orang yang menyeberang pada kawasan Districk 9 Apartement maka sesuai dengan pedoman buku Ahmad munawan maka rekomendasi fasilitas penyeberangan pada kawasan tersebut adalah menyeberang adalah zebra cross. Berdasarkan hasil perhitungan pejalan kaki menyusuri pada kawasan Districk 9 
Apartemen maka saat ini lebar efektif trotoarnya adalah 1.55 meter untuk trotoar disebelah utara dan lebar trotoar efektif yang disebelah selatan adalah 1.54 meter. Berdasarkan hasil analisa kebutuhan parkir sesuai SK Dirjend Hubdat Berdasarkan Sk Dirjend Hubdat maka kebutuhan parkir Districk 9 Apartemen adalah 108 SRP dan kebutuhan lahan Parkir adalah $1350 \mathrm{~m}^{2}$. Berdasarkan SK Walikota Medan Tentang Standard Parkir di Kota Medan standar parkir di pemko medan dinyatakan bahwa setiap 60 $\mathrm{m}^{2}$ luas bangunan Apartement dipusat kota harus menyediakan tempat parkir untuk 1 mobil. lahan parkir yang harus disediakan untuk menunjang operasional Districk 9 Apartemen adalah 1.086,4 $\mathrm{m}^{2}$ sedangkan dalam rencana pembangunan Districk 9 Apartemen menyediakan 1.508,95 $\mathrm{m}^{2}$ sehingga dengan demikian lahan yang akan dialokasikan untuk lahan parkir Districk 9 Apartemen telah memenuhi sesuai dengan SK Walikota Medan untuk menampung kendaraan pada saat operasional Districk 9 Apartement.

\section{DAFTAR PUSTAKA}

Budiadi, A. (2008). Desain Praktis Beton Prategang. Andi, Yogyakarta.

Ilham, N.M. (2008). "Perhitungan Box Girder Beton Prestress Gejayan Fly Over Yogyakarta".

Lin, T.Y., dan Ned H.B. (1988). Desain Struktur Beton Prategang. Edisi ke 3. Jilid 1. Diterjemahkan oleh: Daniel Indrawan M.C.E. Erlangga, Jakarta.

Nawy, E.G. (2001). Beton Prategang Suatu Pendekatan Mendasar. Edisi ke 3. Jilid 1. Diterjemahkan oleh: Bambang Suryoatmo. Erlangga, Jakarta.

Rombach, G. (2002). "Precast segmental box girder bridges with external prestressing: Design and Construction".

Wijaya Karya Beton, PT. (2015). "Dokumentasi Produksi dan Shop Drawing Box Precast Pembanguanan Jalan KA Layang Antara Medan-Araskabu-Kualanamu". Binjai 